\title{
Neuroprotective effect of Tagara, an Ayurvedic drug against methyl mercury induced oxidative stress using rat brain mitochondrial fractions
}

\author{
Dhanoop Manikoth Ayyathan, Rajasekaran Chandrasekaran and Kalaivani Thiagarajan ${ }^{*}$
}

\begin{abstract}
Background: Methyl mercury (MeHg), an important environmental toxicant is implicated in neurological disorders such as Hunter-Russell syndrome and Autism. Therefore, the present work is in search of new drugs that can alleviate MeHg toxicity. In this connection, Tagara, an ayurvedic drug is used for assessing its neuro protective effect against MeHg toxicity.

Methods: In the present study, we assessed the phytochemical contents of Tagara by colorimetric and HPLC analyses. The neuroprotective effect of Tagara on $\mathrm{MeHg}$ induced neurotoxicity was measured in terms of viability by MTT assay and oxidative stress in terms of catalase activity, glutathione and thiobarbituric acid reactive substance levels. Further, the chelating effect of Tagara towards MeHg was performed to identify the molecular mechanism. Statistical analysis was done by statistical package for social sciences (SPSS) version 16.0.

Results: The results demonstrated that Tagara contains significant amounts of phenols and flavonoids. Also, HPLC analysis of Tagara revealed the presence of essential oils such as hydroxyvalerenic and valerenic acids. Our results demonstrated that exposure of rat brain mitochondrial fractions to MeHg resulted in a dose dependent death in MTT assay and $I_{50}$ value was found to be $10 \mu \mathrm{M}$. However, a $250 \mu \mathrm{g}$ dose of Tagara effectively prevented MeHg induced mitochondrial damage. The oxidative stress caused by MeHg results in elevated levels of reactive oxygen species as evidenced by elevated TBARS (Thiobarbituric acid-reactive substances) levels and diminished catalase enzyme activity and glutathione content. However, Tagara at $250 \mu \mathrm{g}$ concentration offsets these alterations caused by MeHg. Further, Tagara also diminished GSH oxidation caused by MeHg, confirming its chelating effect, one of the molecular mechanisms that triggers protection against oxidative damage.

Conclusion: Our results revealed that MeHg induced toxicity is predominantly mediated through oxidative stress mechanism and the propensity of Tagara to abolish such reactions. Hence, we propose that Tagara with a source of potential neuroprotectants may be a useful approach to alleviate MeHg associated neurotoxicity.
\end{abstract}

Keywords: Methyl mercury, Oxidative stress, Tagara, Mitochondrial viability, Neuroprotection

\footnotetext{
* Correspondence: kalaivanit@vit.ac.in

School of Biosciences and Technology, VIT University, Vellore-632014,

Tamilnadu, India
} 


\section{Background}

Mercury is one of the potential environmental xenobiotic toxicants that is implicated in long-term neurological and developmental disorders in both animals and humans [1, 2]. Among different forms of mercury, $\mathrm{MeHg}$ (organic form) is an important neurotoxicant due to its higher entry rate into the CNS compared with inorganic mercurials [3, 4]. Human exposure to methylmercury ( $\mathrm{MeHg}$ ) through consumption of sea foods results in autism spectrum disorders, Alzheimer's disease, Parkinson's disease, Huntington's disease, Minamata disease epilepsy, depression, mood disorders and tremor [4-8].

Current focus of research in the neurotoxicology field is to identify the underlying mechanism behind mercuryinduced neurotoxicity and also to find out the antidotes to counteract the toxic effects. Among the three important molecular mechanisms of MeHg-induced neurotoxicity such as oxidative stress, disruption of calcium homeostasis and impairment of glutamate homeostasis, evidences pointed out that oxidative stress, particularly in mitochondria is a central mechanism $[6,8]$.

Though there are researches related to development of drugs, the treatment for neurological disorders remains wretched due to failure of regeneration of central nervous tissues by modern drugs and their adverse side effects. Because oxidative stress is a common phenomenon in metal toxicity, it is important to understand the interaction between antioxidants and neurotoxicants such as methyl mercury. The benefits associated with intake of antioxidants have been attributed mainly to the antioxidant activity of medicinal plants. Also, some of the Ayurvedic herbs such as Acorus calamus, Nardostachys jatamansi, Herpestis monniera etc., are effective in the treatment of most of the neurological disorders [9].

In this regard, Tagara (Valeriana wallichii of family Valerianaceae), an ayurvedic drug that possesses protective effects on several aspects of brain and nervous conditions is chosen for the present study. It is well used in various pharmaceutical preparations for the treatment of migraine $[10,11]$, insomnia and anxiety [12]. Tagara is also reported to have antioxidant effect [13]. Although studies have documented the various pharmacological activities of Tagara, very little is known about its interaction with $\mathrm{MeHg}$ induced neurotoxicity. Therefore, the intention of the present study is to find out the therapeutic response of Tagara, an ayurvedic drug against methyl mercury induced neurotoxicity. The antioxidants such as phenols and flavonoids present in Tagara were assessed by colorimetric method and the presence of essential oils was confirmed through HPLC. The cell viability was assessed by MTT assay and catalase, glutathione and TBARS levels were also assessed. Also, the chelating effect of Tagara towards MeHg is performed that revealed the molecular mechanism of action of Tagara against $\mathrm{MeHg}$ induced oxidative stress.

\section{Methods}

Animals

Adult Wistar rats (9 months old) were bred in the animal house of Vellore Institute of Technology. All the experimental procedures were carried out in accordance with committee for the purpose of control and supervision of experiments on animal (CPCSEA) guidelines, and all experiments were approved by the institutional animal ethics committee (VIT/IAEC/VII/14). The animals were maintained at $23{ }^{\circ} \mathrm{C}$ on a $12 \mathrm{~h}$ light/dark cycle with free access to water and food (VIT University, Vellore, India).

\section{Chemicals}

Methylmercury (II) chloride, 5, 5' -dithiobis-(2- nitro benzoic acid) (DTNB), glutathione (GSH)-reduced form and 3-(4, 5-dimethyl-2-thiazolyl)-2, 5-diphenyl-2H-tetrazolium bromide (MTT) were purchased from Sigma. All other chemicals used were of analytical grade.

\section{Plant sample preparation}

Tagara, a whole plant powder in the form of capsules was procured from Himalaya Company, Bangalore, India. Tagara powder of $1 \mathrm{mg} / \mathrm{ml}$ concentration was prepared and was determined for total phenolic and flavonoid contents.

\section{Total phenolic content}

The amount of total phenolics present in Tagara was determined using Folin-Ciocalteau (FC) reagent as described using gallic acid as standard [14]. To different concentrations of Tagara, FC and sodium carbonate were added and incubated at room temperature for $20 \mathrm{~min}$. Then, the absorbance was measured at $730 \mathrm{~nm}$. Values are represented as mean $\pm \operatorname{S.E}(n=3)$.

\section{Total flavonoid content}

The amount of total flavonoids present in Tagara was determined using quercetin as standard [15]. To different concentrations of Tagara, potassium acetate and aluminium nitrate were added. After $40 \mathrm{~min}$ of incubation at room temperature, the absorbance was measured at $415 \mathrm{~nm}$. Values are represented as mean $\pm \operatorname{S.E}(n=3)$.

\section{Sample preparation for HPLC analysis}

For HPLCanalysis, $2 \mathrm{~g}$ of fine powder of Tagara was weighed and transferred to a $100 \mathrm{~mL}$ volumetric flask. It was then diluted to volume with methanol: water (80:20) and sonicated for $30 \mathrm{~min}$. Then, it was filtered through a $0.45 \mu \mathrm{m}$ membrane filter [16].

\section{HPLC instrumentation}

HPLC experiments were performed on a YungLin HPLC system equipped with Phenomenex Luna C18, $5 \mathrm{~mm}$ $(4.6 \times 250 \mathrm{~mm})$ column, LC10AT VP pumps, SCL-10AVP 
system controller, SIL-10 AD VP auto injector, SPD-M10 AVP photodiode array detector and class VP software was used [16].

\section{Analytical method for HPLC analysis}

In this method, the mobile phase used was a mixture of methanol and $0.5 \%$ phosphoric acid (80:20). The following parameters were set such as flow rate of $1.5 \mathrm{ml} / \mathrm{min}$, column temperature of $30{ }^{\circ} \mathrm{C}$ and detection wave length at $225 \mathrm{~nm}$. The injection volume used was $20 \mu \mathrm{l}$ and the total run time was $15 \mathrm{~min}$. The chromatographic system was equilibrated by the mobile phase. [16].

\section{Sample preparation for neuro protective property}

Mitochondrial enriched fractions were prepared essentially as described by Franco et al. [17]. Reaction mixture (R1) of $150 \mu \mathrm{L}$ was prepared by incubating $2 \mathrm{mg}$ of mitochondrial enriched protein with different concentrations of $\mathrm{MeHg}(0,5,10,25,50,75$ and $100 \mu \mathrm{M})$ and of Tagara $(10,25,50,100,250$ and $500 \mu \mathrm{g})$ in a medium containing $5 \mathrm{mM}$ HEPES buffer (pH 7.0), $110 \mathrm{mM}$ mannitol, $34 \mathrm{mM}$ sucrose, and $5 \mathrm{mM} \mathrm{KCl}$ for $30 \mathrm{~min}$ at $25^{\circ} \mathrm{C}$. After incubations, following parameters were assessed.

\section{Total protein}

Protein concentration was determined by using Lowry method [18].

\section{MTT assay}

Mitochondrial function was assessed by MTT assay [19]. The reaction mixture (R1) of $150 \mu \mathrm{L}$ was incubated with $150 \mu \mathrm{L}$ of $1.2 \mathrm{mM} \mathrm{MTT}$ for $30 \mathrm{~min}$ at $25^{\circ} \mathrm{C}$. The purple formazan crystal pellets were dissolved in DMSO, and the colour obtained was measured at $550 \mathrm{~nm}$. The results were expressed as percentage viability.

\section{Glutathione content}

Glutathione content was measured by the method of Ellman [20]. The reaction mixture (R1) of $150 \mu \mathrm{L}$ was incubated with $600 \mu \mathrm{L}$ of $10 \%$ trichloroacetic acid. Then it was centrifuged at $4000 \mathrm{rpm}$ for $10 \mathrm{~min}$ at $4{ }^{\circ} \mathrm{C}$. To the supernatant, $300 \mu \mathrm{L}$ of Ellman's reagent and $600 \mu \mathrm{L}$ of $0.1 \mathrm{M}$ phosphate buffer were added. The yellow color developed was read at $412 \mathrm{~nm}$.

\section{TBARS levels}

Lipid peroxidation levels were measured as thiobarbituric acid reactive substances (TBARS) according to the method of Ohkawa [21]. To $150 \mu \mathrm{L}$ of reaction mixture (R1), $0.375 \%$ 2-thiobarbituric acid, $5 \%$ trichloroacetic acid and $0.25 \mathrm{~N} \mathrm{HCl}$ were added and was incubated at $95{ }^{\circ} \mathrm{C}$ for $60 \mathrm{~min}$. Then the tubes were centrifuged at $1000 \mathrm{rpm}$ for $10 \mathrm{~min}$, and the pink color developed was estimated at $535 \mathrm{~nm}$.
Table 1 Total phenolic and total flavanoid contents of Tagara Name TPC (mg of GAE/g of extract) TFC (mg of Quercetin equivalents/g of extract)

\begin{tabular}{lll}
\hline Tagara & $185 \pm 0.07$ & $110 \pm 0.4$
\end{tabular}

\section{Catalase assay}

Catalase enzyme was measured according to the method described by Sinha [22]. To $150 \mu \mathrm{L}$ of reaction mixture (R1), $1.35 \mathrm{ml}$ of $0.01 \mathrm{M}$ phosphate buffer (PH 7.0) and $600 \mu \mathrm{L}$ of $0.2 \mathrm{M}$ hydrogen peroxide were added. After $30 \mathrm{~s}$, $3 \mathrm{ml}$ of dichromate acetic acid mixture (1:3) were added and then heated in a boiling water bath for $10 \mathrm{~min}$. The green color developed was read at $620 \mathrm{~nm}$.

\section{Chelating effect}

The chelating effects of Tagara towards $\mathrm{MeHg}$ were analyzed by an indirect method. $10 \mu \mathrm{M}$ concentration of $\mathrm{MeHg}$ was incubated with GSH $(100 \mu \mathrm{M})$ in the presence or absence of Tagara $(250 \mu \mathrm{g})$ at $25{ }^{\circ} \mathrm{C}$ for $30 \mathrm{~min}$. Then the amount of reduced form of GSH was determined by reaction with 5, 5'-dithiobis-(2-nitrobenzoic acid) that indirectly gives the measure of free mercury [20].

\section{Statistical analysis}

Statistical differences among groups were analyzed by one-way analysis of variance followed by Duncan's multiple range tests when required. Pearson analysis was used to correlate variables. Differences were considered statistically significant when $P<0.05$.

\section{Results}

\section{Total phenol content (TPC)}

Phenolics play a vital role in the free-radical scavenging properties of plants. The total phenolic content in Tagara was found to be $185 \mathrm{mg}$ of Gallic acid equivalents per gram of Tagara (Table 1). (Standard curve equation: $\mathrm{y}=0.069 \times, \mathrm{r}^{2}=0.992$ ).

\section{Total flavonoid content (TFC)}

The total flavonoid content found in Tagara was found to be $110 \mathrm{mg}$ of Quercetin equivalents per gram of Tagara (Table 1). (Standard curve equation: $y=0.139 \times, r^{2}=0.998$ ).

Table 2 Compounds and Retention times

\begin{tabular}{lllll}
\hline Peak no. $\begin{array}{l}\text { Compound } \\
\text { name }\end{array}$ & $\begin{array}{l}\text { Retention time } \\
\text { (Minutes) }\end{array}$ & $\begin{array}{l}\text { Retention time } \\
\text { (Minutes) of } \\
\text { standards }\end{array}$ & Reference \\
\hline 1 & $\begin{array}{l}\text { Hydroxyvalerenic } \\
\text { acid }\end{array}$ & 3.56 & 3.60 & Roy, 1999 \\
2 & Valerenic acid & 11.15 & 11.31 & \\
\hline
\end{tabular}




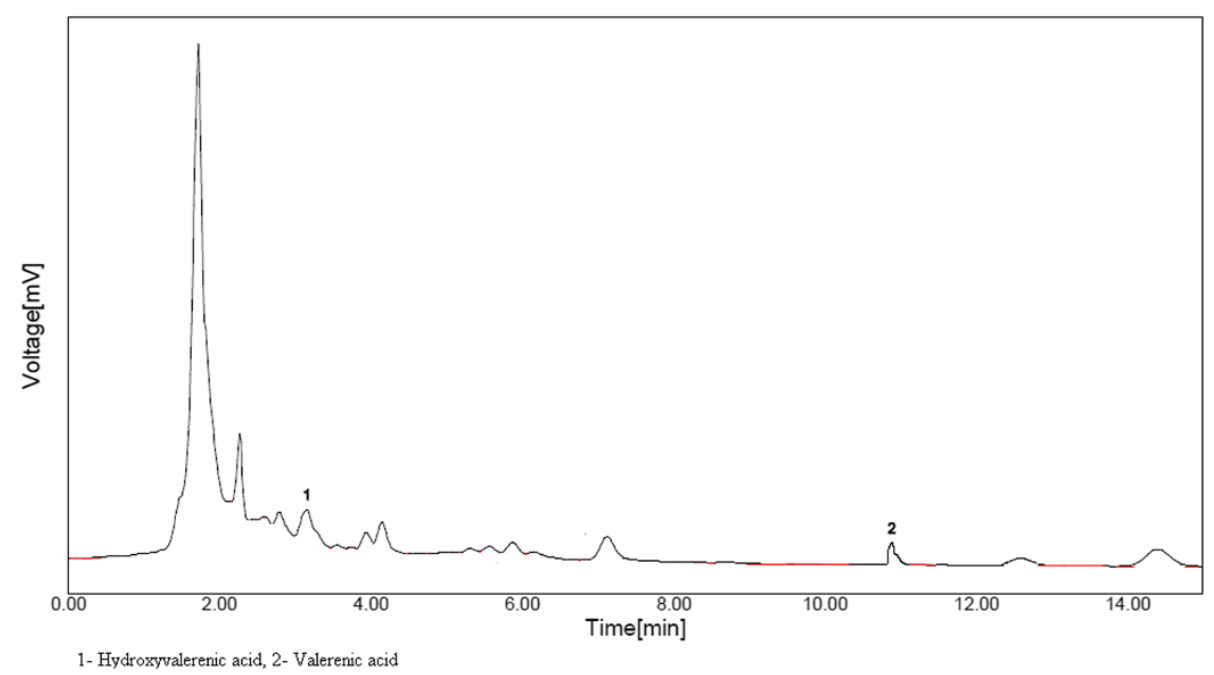

Fig. 1 HPLC Chromatogram of Tagara. 1. Hydroxyvalerenic acid, 2. Valerenic acid

\section{HPLC analysis}

The presence of essential oils at $225 \mathrm{~nm}$ by HPLC was determined in Tagara and compared with published data [16]. By comparing the retention times of the standards, following compounds (Table 2, Fig. 1) were identified in Tagara viz, (hydroxyvalerenic acid and valerenic acid).

\section{Assessment of mitochondrial viability}

In MTT assay, our results indicated that $\mathrm{MeHg}$ decreased the mitochondrial activity in a dose-dependent manner (Fig. 2) and $\mathrm{IC}_{50}$ value was found to be $10 \mu \mathrm{M}$. However, Tagara at $250 \mu \mathrm{g}$ concentrations and positive control quercetin at $250 \mu \mathrm{M}$ restore $\mathrm{MeHg}$ induced mitochondrial dysfunction (Fig. 3).
Protective effect of Tagara against $\mathrm{MeHg}$ induced oxidative stress

The glutathione level was found to be reduced significantly to $51 \%(P<0.05)$ when $\mathrm{MeHg}$ was used (Fig. 4). However, Tagara at $10 \mu \mathrm{g}$ concentration and quercetin at $10 \mu M$ concentration have completely prevented this reduction in glutathione levels.

The activity of catalase was significantly reduced in $\mathrm{MeHg}$ intoxicated group vs. the control group by $-49 \%(P<0.05)$. After treatment with Tagara and positive control quercetin, there is a significant improvement in the catalase activity $v i z,+39$ and $+45 \%$, respectively (Fig. 5).

The TBARS levels are significantly increased in the $\mathrm{MeHg}$ treated group compared with the control group

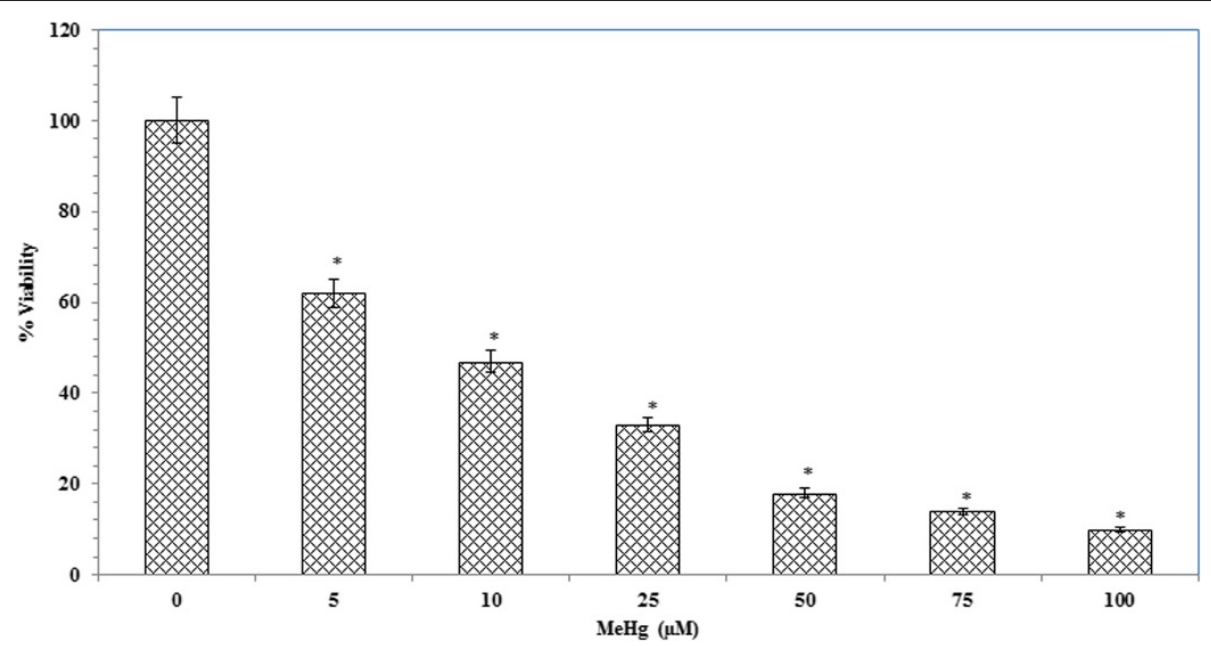

Fig. 2 Influence of MeHg on mitochondrial function. Data are expressed as viability percentage. Values are represented as mean \pm standard error. ${ }^{*}$ indicates statistically different from control $(P<0.05)$ 


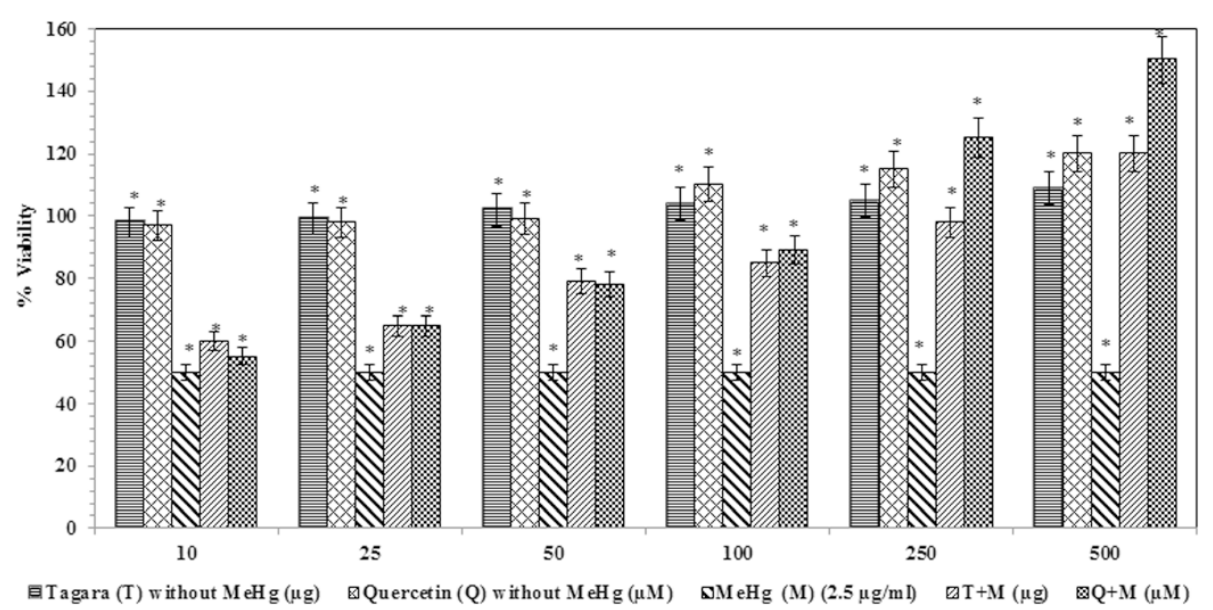

Fig. 3 Neuroprotective property of Tagara against MeHg-induced mitochondrial dysfunction. Data are expressed as percentage of viability. Values are represented as mean \pm standard error. ${ }^{*}$ indicates statistically different from control $(P<0.05)$

by $+128 \%$. After administration of Tagara and positive control quercetin, a significant reduction $(P<0.05)$ was noted compared with the control by +8 and $+14 \%$, respectively (Fig. 6).

\section{Chelating effect}

In order to investigate the chelating effect of Tagara against $\mathrm{MeHg}$, the amount of "free" mercurial in the reaction medium was indirectly measured by using reduced glutathione content. Table 3 shows that Tagara at $250 \mu \mathrm{g}$ concentration was effective in chelating MeHg. The presence of Tagara in the reaction medium changed the oxidative capability of $\mathrm{MeHg}$ that converts reduced glutathione to oxidized form.

\section{Discussion}

Many heavy metals including mercury have the ability to produce ROS which initiate chain reactions that provoke oxidation of biomolecules such as lipids, proteins and nucleic acids [23]. Antioxidants defend against metal toxicity by trapping free radicals and or by chelating metal ions [24]. Therefore, the antioxidants such as total phenolics and flavonoids present in Tagara are estimated in the present study. Our study showed that there is a significant amount of phenolics and flavonoids in Tagara, which are thought to be the potential neuro protectants and thus can be used in the treatment of oxidative stress related neurological diseases.

In addition, the essential oils are also reported to have neuro protective properties. The HPLC results of our

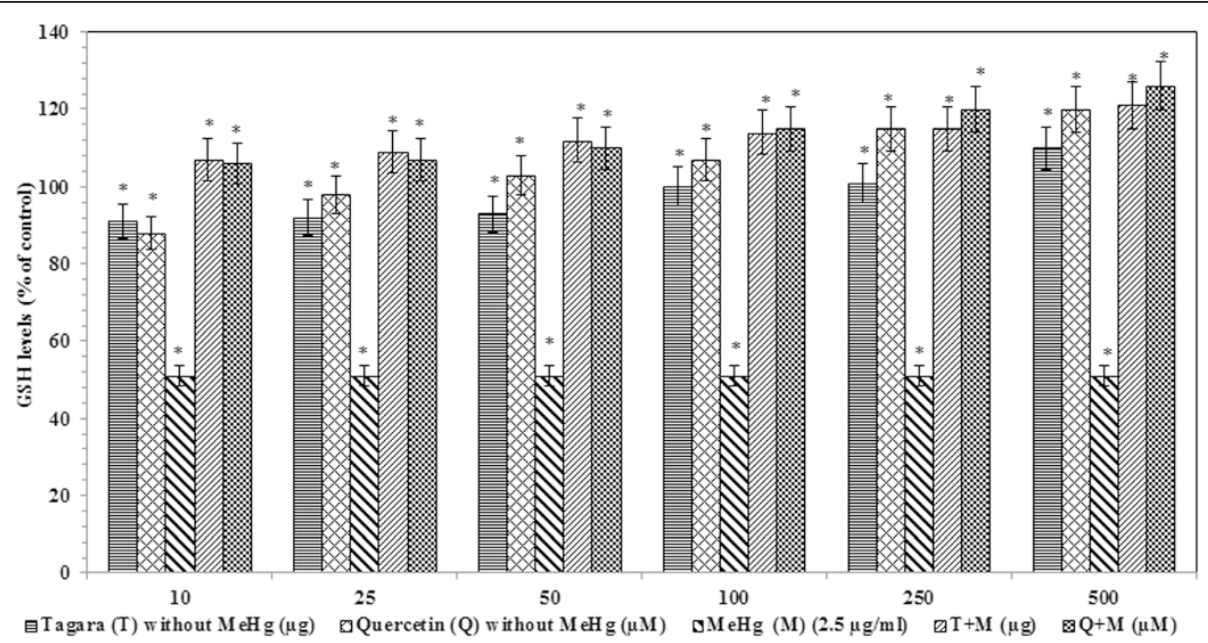

Fig. 4 Glutathione contents in treated and untreated groups with Tagara. Data are expressed as percentage of control. Values are represented as mean \pm standard error. *indicates statistically different from control $(P<0.05)$ 


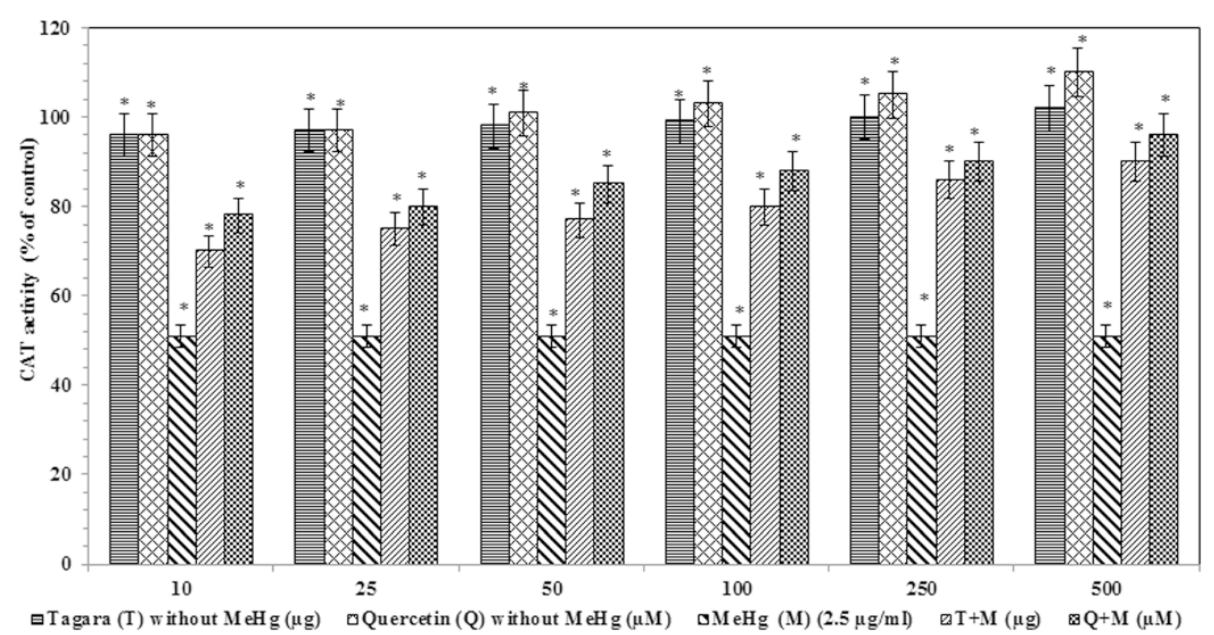

Fig. 5 Catalase activity in treated and untreated groups with Tagara. Data are expressed as percentage of control. Values are represented as mean \pm standard error. ${ }^{*}$ indicates statistically different from control $(P<0.05)$

study also substantiate the presence of essential oils such as hydroxyvalerenic acid and valerenic acid in Tagara. Previous reports also indicated that the roots and rhizomes are highly aromatic and contain valerenic acid that has been shown to inhibit the breakdown of neuro transmitter gamma-aminobutyric acid (GABA) that results in sedation [25].

To study the neuroprotective property of Tagara, isolated rat brain mitochondria a major target for $\mathrm{MeHg}$ induced oxidative stress was used as a model [26]. ROS which are produced as a result of normal oxygen metabolism at higher concentration are important mediators of oxidative stress and cell damage [27]. Our results also showed that oxidative stress, induced by $\mathrm{MeHg}$ results in significant reduction in mitochondrial function. Previous reports also suggested the same [10, 26].

However, the deleterious effects of ROS are counterbalanced by both antioxidant enzymes such as catalase, superoxide dismutase and non-enzymatic antioxidants such as glutathione, vitamins, flavonoids, phenolics etc. [24].

Excessive free radicals play an important role in neural disorders and therefore medicinal plants with rich sources of antioxidants are given considerable importance as they are the important scavengers of free radicals. Many reports suggested that neuroprotective mechanism of bioflavonoids is partly related to their metal chelating and antioxidant properties [28]. Plants also contain important therapeutic metabolites that are involved in brain cell regeneration. Previous study also

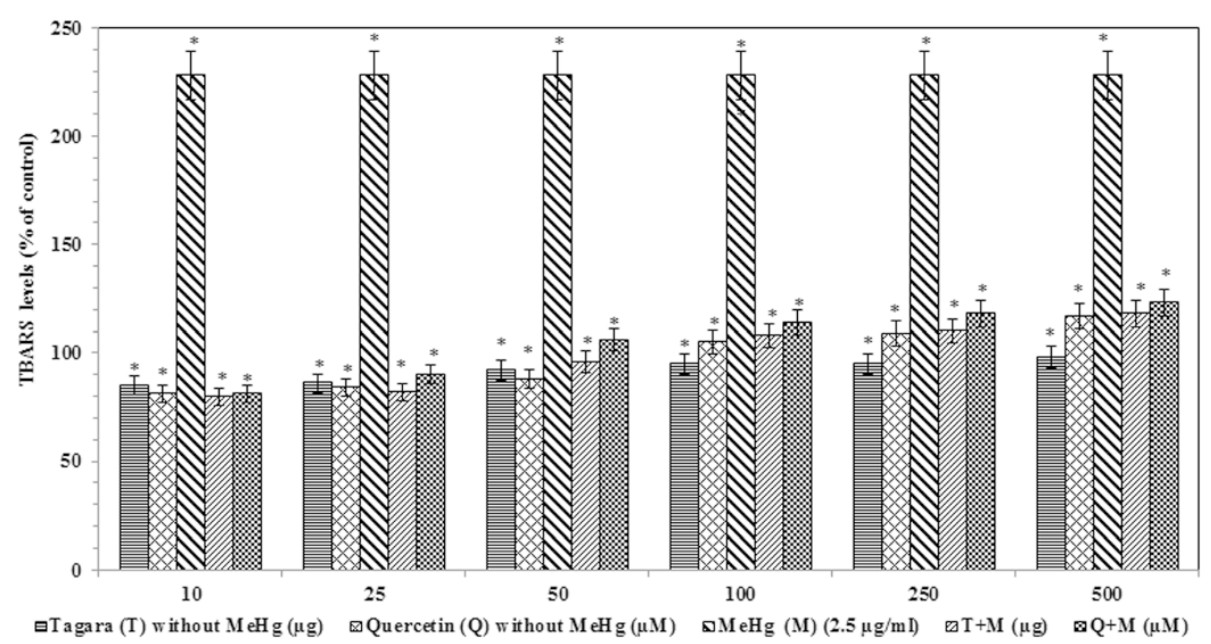

Fig. 6 TBARS levels in treated and untreated groups with Tagara. Data are expressed as percentage of control. Values are represented as mean \pm standard error. *indicates statistically different from control $(P<0.05)$ 
Table 3 Chelating effect of Tagara

\begin{tabular}{lcc}
\hline & $\begin{array}{c}\text { Level of GSH }(\mu \mathrm{mol}) \\
\text { Without Tagara }\end{array}$ & With Tagara at $250 \mu \mathrm{g}$ \\
\hline GSH without MeHg & $100 \pm 1.0$ & $98 \pm 2.0$ \\
GSH with $10 \mu \mathrm{M} \mathrm{MeHg}$ & $46 \pm 1.5^{*}$ & $60 \pm 1.0^{*}$ \\
\hline
\end{tabular}

Student $\mathrm{t}$ test showed significant differencce

*indicates, $P<0.001, n=3$

confirms that the bioactive compound turmerone in turmeric increases neural stem cell growth in the brain and helps in differentiation of neural stem cells to neurons [29].

Therefore in our study, we sought Tagara, an important medicinal herb is responsible for protection against $\mathrm{MeHg}$ induced neurotoxicity, using mitochondrial enriched rat brain fractions. Our results showed that $\mathrm{MeHg}$ induced oxidative stress results in mitochondrial damage by decreasing the defense mechanisms such as reduced glutathione (GSH) content and catalase enzyme levels. This GSH depletion is due to the fact that $\mathrm{MeHg}$ interferes with the uptake of cystine, which is a precursor of GSH synthesis $[30,31]$ and its interaction with GSH as it has high affinity with SH-groups of GSH [32, 33]. The protective effects of GSH are related to its antioxidant capacity and its ability to conjugate with $\mathrm{MeHg}$ for its efflux [34] and therefore its depletion results in cell damage and neurotoxicity. It is interesting to note that there is an increase in GSH content by Tagara ( $250 \mu \mathrm{g}$ concentration), supposed to be a promising neuroprotective agent against MeHg-induced neurotoxicity.

Reports also suggested that, catalase an enzyme that detoxifies hydrogen peroxide are reduced in response with $\mathrm{MeHg}$ whereas, Tagara efficiently restored catalase activiy. This is in accordance with our previous study with Brahmi [35]. Hence, we could presume that the elevation of GSH and catalase enzyme could be one of the major mechanisms by which Tagara counteracts $\mathrm{MeHg}$ toxicity.

It is suggested that oxidative injury, especially lipid peroxidation, via a powerful oxidant (e.g., hydroxyl radicals), may play an important role in cerebellar degeneration during $\mathrm{MeHg}$ intoxication. In the present study, our results indicated that MeHg increased the levels of thiobarbituric acid reactive substances (TBARS), a marker of lipid peroxidation. It has been previously reported that the elevation of TBARS is due to an oxidative injury by hydroxyl radicals [36]. Although the levels of TBARS were enhanced in $\mathrm{MeHg}$ induced neurotoxicity, Tagara decreased these levels in a significant manner.

In addition to the antioxidant properties of Tagara, the ability to chelate mercurial ions represents an important mechanism for neuroprotection. In fact, our results showed that (Table 3) Tagara is able to chelate metal ions and reinforce its therapeutic potential against $\mathrm{MeHg}$ intoxication.

\section{Conclusion}

The data reported here strengthens the antioxidant and protective proficiency of Tagara against $\mathrm{MeHg}$ neurotoxicity. Considering the facts that oxidative stress has been implicated in $\mathrm{MeHg}$ toxicity and medicinal plants are effective in counteracting the toxic effects of $\mathrm{MeHg}$, the use of Tagara may represent an important therapeutic approach. The present study shows that GSH oxidation is a critical phenomenon involved with MeHg induced mitochondrial dysfunction and that the protective effect of Tagara on such process is directly related to its chelating effect. The phytochemical and HPLC analyses showed the presence of phenols and flavonoids, as well as essential oils. These results indicated that Tagara exerts a significant protection against $\mathrm{MeHg}$ induced in vitro neurotoxicity. However, these issues need further investigations on the molecular mechanisms associated with mercurial toxicity and the pharmacological studies of Tagara with respect to mercurial poisoning through cell lines and in vivo studies.

\section{Abbreviations \\ DTNB: 5'-dithiobis-(2- nitrobenzoic acid); GABA: Gamma-aminobutyric acid; GSH: Glutathione; HPLC: High performance liquid chromatography; MeHg: Methyl mercury; MTT: 3-(4,5-dimethyl-2-thiazolyl)-2,5-diphenyl-2H- tetrazolium bromide; ROS: Reactive oxygen species; TBARS: Thiobarbituric acid reactive substances; TPC: Total phenol content; TFC: Total flavonoid content.}

\section{Competing interests}

The authors declare that they have no competing interests.

\section{Authors' contributions}

KT concieved the idea, designed the experiments and drafted the manuscript, DMA carried out the in vitro studies. RC performed the statistical analysis and drafted the manuscript. All authors read and approved the final manuscript.

\section{Acknowledgements}

The authors are thankful to the management of VIT University for their constant support and encouragements.

Received: 26 June 2014 Accepted: 22 July 2015

Published online: 12 August 2015

\section{References}

1. Clarkson TW, Magos L. The toxicology of mercury and its chemical compounds. Crit Rev Toxicol. 2006;36:609-62.

2. Liu W, Xu Z, Deng Y, Xu B, Wei Y, Yang T. Protective effects of memantine against methylmercury-induced glutamate dyshomeostasis and oxidative stress in rat cerebral cortex. Neurotox Res. 2013;24:320-37.

3. Debes F, Budtz-Jorgensen E, Weihe P, White RF, Grandjean P. Impact of prenatal methylmercury exposure on neurobehavioral function at age 14 years. Neurotoxicol Teratol. 2006;28(5):536-47.

4. Aschner M, Syversen T, Souza DO, Rocha JB, Farina M. Involvement of glutamate and reactive oxygen species in methylmercury neurotoxicity. Braz J Med Biol Res. 2007;40:285-91.

5. Ceccatelli S, Daré E, Moors M. Methylmercury-induced neurotoxicity and apoptosis. Chem Biol Interact. 2010;188:301-8.

6. Farina M, Rocha JBT, Aschner A. Mechanisms of methylmercury-induced neurotoxicity: evidence from experimental studies. Life Sci. 2011;89 (15-16):555-63.

7. Xu F, Farkas S, Kortbeek S, Zhang FX, Chen L, Zamponi GW, et al. Mercuryinduced toxicity of rat cortical neurons is mediated through N-methyl-DAspartate receptors. Molecular Brain. 2012;5:30. doi:10.1186/1756-6606-5-30. 
8. Farina M, Avila DS, da Rocha JBT, Aschner M. Metals, oxidative stress and neurodegeneration: a focus on iron, manganese and mercury. Neurochem Int. 2013;62:575-94.

9. Shankar A. Ayurveda for neurological disorders. J Homeop Ayurv Med. 2013;2:130. doi:10.4172/2167-1206.1000130.

10. Morazzoni $P$, Bombardelli E. Valeriana officinalis: traditional use and recent evaluation of activity. Fitoterapia. 1995;66:99-112.

11. Sangeeta PS, Chandra SM, Kanwaljit C. Involvement of nitric oxide (NO) signalling pathway in the antidepressant activity of essential oil of Valeriana wallichii Patchouli alcohol chemotype. Phytomedicine. 2011;18:1269-75.

12. Shalam M, Shantakumar SM, Narasu ML. Pharmacological and biochemical evidence for the antidepressant effect of the herbal preparation Trans-01. Indian J Pharmacol. 2007;39:231-4.

13. Agrawal A. A comparative study of psychotropic drugs and bio-feedback therapy in the prevention and management of psychosomatic disorder, PhD thesis. Varanasi: Banaras Hindu University; 1993.

14. Kujala TS, Loponen JM, Klika KD, Pihlaja K. Phenolics and betacyanins in red beetroot (Beta vulgaris) root: distribution and effect of cold storage on the content of total phenolics and three individual compounds. J Agric Food Chem. 2000;48:5338-42.

15. Nieva MMI, Isla Ml, Sampitro AR, Vattuone MA. Comparison of the free radical-scavenging activity of propolis from several regions of Argentina. J Ethnopharmacol. 2000;109:114.

16. Roy UH. Valerian root, Valeriana officinalis, analytical, quality control and therapeutic monograph. American Herbal Pharmacopoeia. 1999;1-25.

17. Jeferson LF, Hugo CB, James S, Fabiana CM, Thais P, Beatriz GM, et al. Mercurial-induced hydrogen peroxide generation in mouse brain mitochondria: protective effects of quercetin. Chem Res Toxicol. 2007;20:1919-26.

18. Lowry OH, Rosebrough NJ, Farr AL, Randall RJ. Protein measurement with the Folin phenol reagent. J Biol Chem. 1951;193:265.

19. InSug O, Datar S, Koch CJ, Shapiro IM, Shenker BJ. Mercuric compounds inhibit human monocyte function by inducing apoptosis: evidence for formation of reactive oxygen species, development of mitochondrial membrane permeability transition and loss of reductive reserve. Toxicology. 1997:124:211-24

20. Ellman GL. Tissue sulfhydryl groups. Arch Biochem Biophys. 1959;82:70-7.

21. Ohkawa $H$, Ohishi $N$, Yagi K. Assay for lipid peroxides in animal tissues by thiobarbituric acid reaction. Anal Biochem. 1979;95:351-8.

22. Sinha AK. Colorimetric assay of catalase. Anal Brochem. 1972;47:389-94.

23. Kalia K, Flora SJS. Strategies for safe and effective treatment for chronic arsenic and lead poisoning. J Occup Hlth. 2005;47:1-21.

24. Flora SJS. Structural, chemical and biological aspects of antioxidants for strategies against metal and metalloid exposure. Oxid Med Cell Longev. 2009:2(4):191-206. doi:10.4161/oxim.2.4.9112.

25. Surajit S, Koushik R, Yogendra K, Shilpa G, Kauser H, Kumar S, et al. Valeriana wallichii root extract improves sleep quality and modulates brain monoamine level in rats. Phytomedicine. 2012;19:924-9.

26. Aschner M, Syversen T. Methylmercury: recent advances in the understanding of its neurotoxicity. Ther Drug Monit. 2005;27:278-83.

27. Poli G, Leonarduzzi G, Biasi F, Chiarpotto E. Oxidative stress and cell signalling. Curr Med Chem. 2004;11:1163-82.

28. Graziano JH, Lolacono NJ, Moulton T, Mitchell ME, Slavkovich V, Zarate C. Controlled study of meso-2, 3-dimercaptosuccinic acid for the management of childhood lead intoxication. J Pediatr. 1992;120:133-9.

29. Hucklenbroich J, Klein R, Neumaier B, Graf R, Fink GR, Schroeter M, et al. Aromatic-turmerone induces neural stem cell proliferation in vitro and in vivo. Stem Cell Research \& Therapy. 2014;5:100.

30. Shanker $G$, Aschner M. Identification and characterization of uptake systems for cystine and cysteine in cultured astrocytes and neurons: evidence for methylmercury-targeted disruption of astrocyte transport. J Neurosci Res. 2001;66:998-1002.

31. Allen JW, Shanker G, Tan KH, Aschner M. The consequences of methylmer-cury exposure on interactive functions between astrocytes and neurons. Neurotoxicology. 2002;23:755-9.

32. Shanker G, Syversen T, Aschner JL, Aschner M. Modulatory effect of glu-tathione status and antioxidants on methylmercury-induced free radical formation in primary cultures of cerebral astrocytes. Brain Res Mol Brain Res. 2005;137:11-22.

33. Sumi D. Biological effects of and responses to exposure to electrophilic environmental chemicals. J Health Science. 2008;54:6
34. Heggland I, Kaur P, Syversen T. Uptake and efflux of methyl mercury in vitro: comparison of transport mechanisms in C6, B35 and RBE4 cells. Toxicol In Vitro. 2009;23:1020-7.

35. Ayyathan DM, Chandrasekaran R, Thiagarajan K. Neuroprotective effect of Brahmi, an ayurvedic drug against oxidative stress induced by methyl mercury toxicity in rat brain mitochondrial-enriched fractions. Nat Prod Res. 2015;29(11):1046.

36. Yamashita T, Ando Y, Nakamura M, Obayashi K, Terazaki H, Haraoka K, et al. Inhibitory effect of a-tocopherol on methylmercury-induced oxidative stress. Environ Health Prev Med. 2004;9:111-7.

\section{Submit your next manuscript to BioMed Central and take full advantage of:}

- Convenient online submission

- Thorough peer review

- No space constraints or color figure charges

- Immediate publication on acceptance

- Inclusion in PubMed, CAS, Scopus and Google Scholar

- Research which is freely available for redistribution 